\title{
TRANSLATION DISCOURSE 4.0: VARIETY OF FORMATS, GENRES AND TRENDS
}

\author{
Elina Yu. Novikova \\ Volgograd State University, Volgograd, Russia \\ Anna P. Naumova \\ Volgograd State University, Volgograd, Russia
}

\begin{abstract}
The article considers the specific character of modern translation discourse, trends and opportunities of realization in the era of changes and global challenges. The relevance of the article is determined by the need to establish common and distinctive forms of expression and formats of translation discourse. The representative sources of three communicatively active discursive practices constitute the empirical base of the paper: scientific / translation studies translation discourse; professional / industry translation discourse; didactic translation discourse. The textual material of the discourse under consideration is analyzed in order to identify thematic dominants of three subtypes under consideration. The similarities and differences of the topics discussed by the translation community within the framework of the selected discursive practices are determined. Sources of translation discourse in Russian and German linguistic cultures were also involved in the analysis to identify common and distinctive features. The analysis revealed the tendency of the Russian-language translation discourse to be a more profound scientific search and substantiation of translation problems, and, on the contrary, the tendency of the German- and English-language discourses to discuss applied issues. The analyzed subtypes of translation discourse reveal certain unifying features: current challenges reaction rapidity, new phenomena and trends in society. However, these subtypes have translation tools of their own, traditions and formats that shape thematic dominants of each direction of the discourse. Thus, the paper revealed the dynamic nature of the discourse, on the one hand, and its sustainable development, on the other.

Key words: translation discourse, didactics of translation, professional community, communication, translation studies.

Citation. Novikova E.Yu., Naumova A.P. Translation Discourse 4.0: Variety of Formats, Genres and Trends. Vestnik Volgogradskogo gosudarstvennogo universiteta. Seriya 2. Yazykoznanie [Science Journal of Volgograd State University. Linguistics], 2021, vol. 20, no. 3, pp. 5-17. (in Russian). DOI: https://doi.org/10.15688/jvolsu2.2021.3.1

\section{ПЕРЕВОДЧЕСКИЙ ДИСКУРС 4.0: РАЗНООБРАЗИЕ ФОРМАТОВ, ЖАНРОВ И ТРЕНДОВ}

\author{
Элина Юрьевна Новикова
}

Волгоградский государственный университет, г. Волгоград, Россия

Анна Петровна Наумова

Волгоградский государственный университет, г. Волгоград, Россия 
Аннотация. В статье показаны специфика современного переводческого дискурса, тренды и возможности реализации в эпоху перемен и глобальных вызовов. Актуальность работы обусловливается необходимостью установления общих и отличительных тем и форматов переводческого дискурса. Материалом исследования послужили тексты трех коммуникативно активных подвидов переводческого дискурса: 1) научного / переводоведческого переводческого дискурса; 2) профессионального / отраслевого переводческого дискурса; 3) дидактического. Текстовый массив рассматриваемого дискурса изучен с целью выявления его тематических доминант в трех указанных подвидах. Установлены сходства и различия обсуждаемых переводческим сообществом тем в рамках выделенных дискурсивных практик. К анализу привлекались также источники переводческого дискурса на материале русскоязычной и немецкоязычной лингвокультур для выявления общности или расхождений. Определено, что в русскоязычном переводческом дискурсе отражен более глубокий, чем в иноязычных дискурсах, научный поиск, дано обоснование переводческих проблем и, напротив, в немецкоязычном и англоязычном дискурсах актуализируются практически значимые вопросы. Анализируемые подвиды переводческого дискурса обнаруживают определенные унифицирующие черты: быстрота реакции на актуальные вызовы, новые феномены и тренды общества. В то же время они имеют собственный инструментарий, традиции и форматы, задающие тематические доминанты каждого из направлений дискурса. В результате исследования выявлены такие черты, как динамичность дискурса и устойчивость его развития.

Ключевые слова: переводческий дискурс, дидактика перевода, профессиональное сообщество, коммуникация, переводоведение.

Цитирование. Новикова Э. Ю., Наумова А. П. Переводческий дискурс 4.0: разнообразие форматов, жанров и трендов // Вестник Волгоградского государственного университета. Серия 2, Языкознание. - 2021. T. 20, № 3. - C. 5-17. - DOI: https://doi.org/10.15688/jvolsu2.2021.3.1

\section{Введение}

Актуальное для современной науки дискурсивное осмысление коммуникации детерминирует рассмотрение переводческой отрасли с позиций дискурсивной лингвистики. В ряде лингвистических исследований последних лет обозначены границы переводческого дискурса, с одной стороны, и унифицировано понятие «переводческий дискурс» (далее ПД) - с другой. Одна из самых распространенных трактовок переводческого дискурса фокусируется на переводном дискурсе, в основе которого лежит технология перевода. Так, А.А. Каразия трактует переводной дискурс с позиции коммуникации, при которой в процессе переводческой деятельности появляется переводной текст [Каразия, 2016]. Термин «переводной дискурс» используется и Н.К. Гарбовским, который имеет иной взгляд на данное понятие и рассматривает такой дискурс как совокупность переводных текстов в одной лингвокультуре, они вторичны по отношению к текстам другой лингвокультуры и в значительной степени отличаются от первичных текстов «своей» лингвокультуры [Гарбовский, 2012]. Идеи Н.К. Гарбовского получили дальнейшее развитие в работах Е.С. Краснопеевой, которая для переводного дискурса вво- дит понятие «абстрактный конструкт» и рассматривает реализацию такого дискурса в дискурсивных пространствах большинства культур [Краснопеева, 2015, с. 110]. При таком подходе учитывается ситуативная обусловленность конструкта, которая задает специфику переводческого действия, что в определенной степени коррелирует с концепцией дискурсивной зависимости переводческого действия. Представители данного исследовательского направления трактуют ПД как дискурсивно зависимое коммуникативное действие, как «переводческое пространство», в котором факторы дискурса (спортивного, туристического, экономического, социального, технического, политического и др.) влияют на принятие переводческого решения [Кушнина, 2009; Кушнина, Аликина, 2010; Левицкий, 2017; Митягина, 2017; Новикова, 2017; Milton, 2004; Wolf, Fukari, 2007]. Переводчик выступает агентом дискурса, он наделен дискурсивным мышлением, как любая языковая и коммуникативная личность, и координирует коммуникативный сценарий конкретного дискурса. Важно отметить, что в результате переводческого действия создается переводческое пространство, отражающее особенности, признаки и конвенции коммуникативного акта. Такое пространство задает рамочные усло- 
вия переводческой программы, которая имеет динамичный характер и модифицируется в каждом конкретном случае.

В науке получил распространение и подход, при котором ПД рассматривается как разновидность аргументативного дискурса [Воскобойник, 2004; Куницына, 2009; Писанова, 2011; Гарбовский, 2010; 2012; Мишкуров, 2012; и др.]. Предметом исследования выступают переводческие комментарии, предисловия и прочие письменные сопровождения к тексту перевода. В таких исследованиях анализируются переводческие действия применительно к художественным произведениям конкретных авторов, то есть исследуется художественный переводческий дискурс. В русле такого подхода Е.Ю. Куницына обозначает переводческий дискурс как «пространство игры и метаигры переводчика» [Куницына, 2018, с. 293].

Аргументативность, будучи конститутивным признаком переводческого дискурса, позволяет смещать вектор исследования в сторону аргументативно-диалогичного дискурса. Представители рассматриваемого направления исследуют диалогическое взаимодействие переводчика с другими акторами коммуникации (заказчиками, клиентами, переводчиками и др.). Благодаря стратегиям аргументативного убеждения переводчика участники коммуникации понимают и адекватно воспринимают необходимость / целесообразность / невозможность и т. п. переводческих услуг [Дондукова, 2012].

Современный формат коммуникации без границ, в том числе в глобальной сети Интернет, создает возможность изучения профессионального дискурса переводчика в рамках деловой коммуникации (см., например: [Наумова, 2013; Митягина, Наумова, 2019]). В фокусе внимания лингвистов оказывается общение специалистов-переводчиков между собой, осуществляемое в целях оптимизации профессиональной деятельности [Наумова, 2016]. Такое взаимодействие реализуется в широком жанровом диапазоне: от научной статьи, выступлений на конференциях до интернет-блогов переводчиков. В пределах профессионального дискурса переводчиков реализуется переводоведческий дискурс, основным критерием которого выступает теоретическое осмысление перевода.
В качестве составляющей ПД может быть рассмотрена и дидактически ориентированная коммуникация о переводе и переводчиках.

Понимание сложной природы ПД, его гетерогенный характер и многоформатность критериев, конститутивных признаков, параметров и дискурсивных практик приводят исследователей к трактовке ПД как метадискурсивной переводческой эпистемы, как сложного эпистемического конструкта, формирующего многогранный переводческий ландшафт [Власенко, 2015, с. 136]. Именно такое понимание ПД принято в нашем исследовании.

В рамках предлагаемого исследования обратимся к рассмотрению ПД с учетом форматов и трендов переводческой деятельности в быстро меняющихся условиях эпохи 4.0. Актуальность исследования объясняется дефицитом переводоведческих исследований интегративного характера, способствующих гибкому восприятию современных лингвистических, социокультурных, технологических процессов в практической деятельности переводчиков и ее адекватному отражению в теории. Особый исследовательский интерес вызывают конгруэнтность, диффузность и полидискурсивность ПД, соединяющего множество дискурсивных практик, каждая из которых имеет недостаточное освещение в исследованиях теории перевода.

Дискурсивные практики ПД представляют собой системообразующий текстовый континуум, формируемый участниками дискурса в процессе профессиональной коммуникации переводчиков, переводоведов и преподавателей перевода о технологии перевода и способах оптимизации качества переводного текста; новых переводческих теориях и моделях; новых методических и дидактических подходах, соответствующих современным трендам рынка переводческих услуг, и др. В связи с этим эвристичность приобретает системное описание доминантных дискурсивных практик с учетом социокоммуникативных характеристик дискурса ввиду его очевидного социального взаимодействия в разных профессиональных контекстах. Цель исследования заключается в установлении направлений тематического развития современного ПД в дискурсивных практиках трех подвидов ПД: научном пе- 
реводоведческом; профессиональном / отраслевом; дидактическом.

Исследование вносит вклад в развитие нового направления науки о переводе - интегративного переводоведения; в разработку гибридной методологии и инструментария для исследования дискурсивных практик переводческой деятельности; позволяет уточнить дискурсивно значимые конститутивные признаки и жанровую парадигму переводческого дискурса, типологизировать переводческие действия и деятельность в онлайн-пространстве эпохи 4.0.

\section{Материалы и методы исследования}

Полемичность анализа ПД определила границы предпринимаемого исследования, а также обусловила выбор методов и отбор источников эмпирического материала для анализа, критериями которого послужили:

- востребованность в профессиональном переводческом сообществе;

- отсутствие узкоформатной направленности;

- актуальность, репрезентативность, достоверность и многочисленность представленных данных;

- межкультурный характер;

- устойчивый характер коммуникативной активности.

Материал исследования дает представление о лингвокультурной специфике анализируемого дискурса, к анализу привлекались русскоязычные, немецкоязычные и англоязычные источники, что позволило определить сходства и различия ПД в неблизродственных лингвокультурах.

Анализ переводоведческого ПД проводился на материале тематических изданий научных трудов 2019-2020 гг.: научный журнал «Вестник Московского Университета. Серия 22, Теория перевода» за 2020 г.; сборник материалов IV Международной научнопрактической конференции «Переводческий дискурс: междисциплинарный подход», проходившей в Симферополе 23-25 апреля 2020 г.; сборник материалов конференции союза устных и письменных переводчиков Германии «Übersetzen und Dolmetschen 4.0. Neue Wege im digitalen Zeitalter», проходившей в 2019 году.
Указанные источники представляют собой крупные серийные издания, посвященные актуальным проблемам теории и практики перевода и востребованные исследователями.

Анализ профессионального ПД проводился с использованием материалов журнала практикующих переводчиков «Мосты» в 2020 г., переводческих конференций «Translation Forum Russia» (2020) и «UTIC» (2020), интернет-форума на крупнейшем мировом переводческом онлайн-ресурсе Proz.com. Обращение к указанным источникам объясняется их практикоориентированным характером: на этих дискуссионных площадках высокого статуса происходит обмен опытом практикующих переводчиков, обсуждение актуальных вопросов отрасли, презентация переводческих трендов действующими переводчиками и представителями переводческих компаний. Кроме того, интернет-форум, как один из наиболее широких и многоаспектных форматов ПД, дает возможность обсуждать конкретные переводческие проблемы и варианты переводческих решений в тех или иных конкретных ситуациях.

Дидактический ПД характеризуется на основе источников, адресованных преподавателям перевода: материалы вебинаров и семинаров Ассоциации преподавателей перевода, материалы общероссийского совещания по подготовке переводчиков (СПР); учебники по переводу, опубликованные издательством «Р.Валент» в 2019-2020 годы.

Для достижения поставленной цели в исследовании применялись контент-анализ и дискурсивный анализ, эмпирический материал отобран методом сплошной выборки. В работе использовался также прием количественных подсчетов, позволивший определить долю статей на определенную тему в общем массиве исследуемых публикаций. Для статей на определенную тему, представленную единичными публикациями (1-3), используется маркер «+» (тема отражена в публикациях, но эпизодически), для статей с частотностью до $50 \%$ от общего объема анализируемого материала - «++» (тема отражена в публикациях достаточно часто), для статей с частотностью свыше $50 \%$ от общего объема анализируемого материала - «+++» (тема отражена в публикациях очень часто). 


\section{Результаты и обсуждение}

Тематические доминанты переводческого дискурса продемонстрируем в ходе анализа трех его подвидов: научного / переводоведческого ПД; профессионального / отраслевого ПД; дидактического ПД.

\section{Научный / переводоведческий ПД}

Переводоведческий дискурс в целом отличается широтой подходов и исследовательских интересов как отечественных, так и зарубежных переводоведов. Научный дискурс по теории перевода реализуется в монографиях, статьях, материалах конференций и др. Выявить тренды переводоведения во всей полноте вряд ли представляется возможным, поэтому сконцентрируем наше внимание на ограниченном, но весьма репрезентативном материале, который был выбран нами для анализа. Научный ПД реализуется как в письменной (научные публикации), так и устной (выступления на конференциях) формах коммуникации. Эмпирическим материалом в исследовании стали научные публикации.

Так, научный журнал «Вестник МГУ. Серия 22, Теория перевода» (источник I) специализируется на рассмотрении теоретических и практических аспектов перевода, ориентирован в большей степени на переводоведов и имеет ограниченный круг авторов. 2020 г. внес коррективы в профиль профессии переводчика, что отразилось в том числе и на специфике научного ПД. Быстро меняющиеся условия переводческой деятельности в сторону ее дигитализации и автоматизированной обусловленности находят свое мгновенное отражение и описание в научном переводоведческом дискурсе. Однако проведенный анализ публикационной активности журнала и тематических доминант, представленных в нем, показывает приверженность журнала традициям классического переводоведения. Об этом свидетельствуют рубрики журнала в выпусках 1-4 за 2020 г.: 75 лет синхронному переводу; трансдисииплинарная наука о переводе; методология перевода; история перевода; переводческая критика; лингвистические и культурологические аспекты перевода; вопросы терминологии; об- щая теория перевода; к 75-летию победы в Великой Отечественной войне. В данных рубриках частотны статьи, посвященные технологии перевода, частным переводческим проблемам, дидактике перевода и различным аспектам художественного (включая поэтический) перевода.

Сборник материалов IV Международной научно-практической конференции «Переводческий дискурс: междисциплинарный подход», Симферополь, 23-25 апреля 2020 г. (источник II), в отличие от «Вестника МГУ», охватывает более широкую аудиторию авторов, отражает на своих страницах многообразие тем и исследовательских ракурсов. Данный сборник формируется по материалам регулярно проводимой конференции, востребован среди лингвистов и переводоведов, о чем свидетельствует количество включенных в него публикаций (110 статей). Наиболее распространенные темы в сборнике, не имеющем рубрикации, отражают общие проблемы художественного перевода, аудиовизуального перевода, вопросы методики и дидактики, а также частные переводческие проблемы.

Сборник трудов, опубликованный по итогам ежегодной конференции, организованной Германским союзом устных и письменных переводчиков (источник III), представляет результаты работы зарубежных переводоведов и переводчиков (113 статей). В 2020 г. конференция была посвящена анализу профессии переводчика в современном цифровом мире. В сборнике представлены следующие рубрики: Влияние внешних факторов на взаимодействие переводчиков с клиентами; Создание контента в эпоху 4.0; Машинный перевод, автоматический перевод; Специальные языки и машинный перевод; Устный перевод; Компетенции и позиционирование на рынке услуг; Маркетинг; Защита данных; Эргономика, Вопросы здоровья. Данные рубрики сбалансированы по количеству статей, однако большинство тем публикаций отражают проблемы машинного перевода и информационных технологий в переводе (устном и письменном). Следует отметить также, что все статьи сборника имеют исключительно практико-ориентированный характер, публикации, посвященные узко специальным научным темам, истории перевода, художе- 
ственному переводу, вопросам дидактики, аудиовизуальному переводу и др., не представлены.

Обобщим полученные результаты в таблице 1.

Результаты анализа актуального научного ПД позволяют установить следующее:

1) наблюдаются культурологические различия в освещении актуальных тем, связанных с профессией переводчика. Если научные публикации в источниках I и II имеют смешанный характер (научный и практический), то в источнике III они ориентированы на решение прикладных задач;

2) большинство опубликованных в источниках I и II материалов посвящено вопросам художественного перевода, в то время как в источнике III внимание полностью сконцентрировано на цифровой составляющей переводческой профессии XXI в., что, вероятно, объясняется заявленной темой конференции;

3 ) единичными публикациями представлено дискурсивно обусловленное переводове- дение, то есть наблюдается сниженный интерес к анализу переводческого действия в различных дискурсах;

4) темы здоровья переводчика, менеджмента качества, новых технологий в устном переводе и вопросы взаимодействия с заказчиком отражены в публикациях зарубежных авторов (источник III) и не представлены в российских изданиях (источники I и II). Это является показателем смены исследовательского фокуса зарубежных переводоведов в сторону изучения реальных условий и проблем профессии, а не теоретических основ перевода.

\section{Профессиональный / отраслевой ПД}

Профессиональный / отраслевой ПД представлен в трех форматах: письменном, устном и интернет-опосредованном. Данная диверсификация способов профессионального взаимодействия обусловлена фундаментальной целью анализируемого подвида ПД - оптимизацией переводческой деятельности на

\section{Таблица 1. Тематические доминанты научного / переводоведческого ПД}

\section{Table 1. Thematic dominants of scientific / translation studies translation discourse}

\begin{tabular}{|l|c|c|c|}
\hline \multicolumn{2}{|c|}{ Темы } & \multicolumn{2}{c|}{ Источники } \\
\cline { 2 - 4 } & I & II & III \\
\hline Технология перевода / трансформации / стратегии & +++ & + & - \\
\hline Художественный перевод & +++ & +++ & - \\
\hline Поэтический перевод & +++ & +++ & - \\
\hline История перевода в разных странах & ++ & + & - \\
\hline Преподавание синхронного перевода & ++ & - & - \\
\hline Единицы перевода & ++ & ++ & - \\
\hline Преподавание перевода / вопросы методики и дидактики & ++ & ++ & ++ \\
\hline Синхронный перевод как особый вид перевода & + & - & - \\
\hline Социальная роль переводчика & + & - & - \\
\hline Искусственный интеллект и перевод & + & - & +++ \\
\hline Цифровизация и перевод & + & - & +++ \\
\hline Машинный перевод & + & - & +++ \\
\hline Война и перевод & + & - & - \\
\hline Устный перевод & + & + & - \\
\hline Перевод библии & + & + & - \\
\hline Аудиовизуальный перевод & - & +++ & - \\
\hline Реклама как переводческая проблема & - & + & - \\
\hline Перевод в различных дискурсах (музейный, политический, & - & + & - \\
туристический и др.) & & & + \\
\hline Переводческая отрасль, бизнес, рынок, фриланс & - & - & +++ \\
\hline Качество перевода & - & - & + \\
\hline Менеджмент терминологии & - & - & ++ \\
\hline Устный перевод и новые технологии & - & - & ++ \\
\hline Защита данных & - & - & + \\
\hline Вопросы здоровья, эргономии & - & - & ++ \\
\hline Взаимодействие с заказчиками и клиентами & - & ++ \\
\hline
\end{tabular}


всех этапах ее реализации. В письменной форме данная цель реализуется в жанре статьи. На страницах профильного журнала «Мосты» (источник IV), публикуемого издательством «Р.Валент», авторы статей - практикующие переводчики, преподаватели перевода - высказывают свою точку зрения по актуальным вопросам переводческой отрасли, делятся опытом и рассуждают о будущем профессии. Несмотря на асинхронный характер письменной коммуникации в жанре статьи, отмечается оперативное своевременное освещение актуальных вопросов, наличие постоянных рубрик На злобу дня; Переводя культуру; Анализ практики; Подготовка переводчика; Исторический музей, а также вариативных рубрик в рамках каждого выпуска.

Качественной спецификой состава организаторов переводческих конференций Translation Forum Russia (источник V) и Ukrainian Translation Industry Camp (источник VI) - Бизнес-бюро Ассоциации переводчиков (Екатеринбург, Россия) и Бюро переводов InText (Днепр, Украина) - определяется ключевое тематическое направление выступлений участников: перевод как бизнес. Руководители переводческих компаний, ведущие менеджеры, разработчики и ритейлеры переводческого программного обеспечения рассказывают о своих достижениях и продуктах и за- дают тренды развития профессии. Так, в программе обеих указанных конференций отмечается наличие схожих направлений работы: Бизнес-поток / Бизнес в сфере перевода и локализации, Технологический поток / Технологии перевода и локализация. Однако несмотря на коммерческо-деловой характер данных мероприятий, в программе также представлено направление, отражающее прикладной аспект переводческой деятельности: Мастерство перевода и языковые секции / Искусство перевода.

Форум является наиболее разнообразным жанром ПД с точки зрения тематики. В результате контент-анализа форумов крупнейшего мирового переводческого онлайн-ресурса Proz.com (источник VII) выявлено, что обсуждаемые вопросы сгруппированы в несколько крупных разделов: Перевод как искусство и бизнес; Технические форумы; Форумы на других языках (кроме английского); Форумы по странам. Каждый из них содержит подразделы, в которых затрагиваются актуальные вопросы, связанные с индустрией и мастерством перевода.

Результаты проведенного анализа профессионального / отраслевого ПД, систематизированного в таблице 2 , позволяют установить следующее:

\section{Таблица 2. Тематические доминанты профессионального / отраслевого ПД}

\section{Table 2. Thematic dominants of professional / industry translation discourse}

\begin{tabular}{|l|c|c|c|c|}
\hline \multicolumn{2}{|c|}{ Темы } & \multicolumn{3}{c|}{ Источники } \\
\cline { 2 - 5 } & IV & V & VI & VII \\
\hline Своевременный рынок переводов и прогнозы его развития & + & + & + & + \\
\hline Новые навыки перевода в условиях кризиса & + & + & + & + \\
\hline Прикладные аспекты методики письменного перевода & + & + & - & + \\
\hline Аудиовизуальный перевод & + & - & + & + \\
\hline Анализ переводов художественных произведений, песен & + & - & - & + \\
\hline Организационно-правовые аспекты подготовки переводчиков & + & - & - & - \\
\hline Дидактические аспекты подготовки переводчиков & + & - & - & - \\
\hline Перевод в исторической ретроспективе & + & - & - & - \\
\hline Удаленный перевод & + & - & - & + \\
\hline Перевод субтитров & - & + & + & + \\
\hline Технический перевод & - & + & - & + \\
\hline Особенности работы с САТ-программами & - & + & - & + \\
\hline Переводческий менеджмент в организации & - & + & - & + \\
\hline Локализация & - & + & - & + \\
\hline Потребители переводческих услуг & - & + & - & + \\
\hline Устный перевод & - & - & + & + \\
\hline Поиск и обсуждение вариантов перевода & - & - & - & + \\
\hline Здоровье и образ жизни переводчиков & - & - & - & + \\
\hline
\end{tabular}


1) широкий спектр обсуждаемых тем свидетельствует об активном развитии переводческой сферы как производственной отрасли современного общества (различные аспекты подготовки переводчиков, организационностратегические вопросы ведения переводческого бизнеса);

2) прикладные аспекты непосредственно переводческого процесса (подбор варианта перевода, новые взгляды на существующие теоретические положения) обсуждаются в трех форматах; обращение к письменному, устному или интернет-опосредованному каналам коммуникации зависит от дискурсивных целей, которые реализует участник переводческого сообщества;

3) темы материалов условно можно разделить на два крупных блока: перевод как искусство и перевод как бизнес; при этом стоит отметить появление новых тем, связанных со здоровьем переводчиков, а также современными вызовами человечества.

\section{Дидактический ПД}

Данный подвид ПД отражает коммуникацию преподавателей устного и письменного перевода на платформах профессиональных сообществ, в рамках встреч, семинаров, вебинаров, организованных для обсуждения методических и дидактических аспектов подготовки переводчиков, а также продукты дидактической работы - учебники и учебные пособия. Ассоциация преподавателей перевода в течение года проводит различные мероприятия по оптимизации деятельности преподавателей в вузе и подготовке переводчиков, материалы представлены на сайте (источник VIII). Общероссийское совещание по вопросам подготовки переводчиков проводится раз в год с целью обсуждения повестки дня и поиска решений сложным как организационным, так и методическим вопросам, материалы ОРС размещены на сайте (источник IX). Результатом подобных встреч становятся реализованные и апробированные подходы в дидактике, отраженные в учебниках, учебных пособиях и научных публикациях. К анализу привлекались работы, опубликованные издательством «Р.Валент» в 2019-2020 гг. (источник Х), которое специа- лизируется на издании словарей, учебных пособий, связанных с переводоведением и обучению переводу, и тем самым способствует развитию современного переводоведения.

В результате сопоставительного изучения указанных выше ресурсов определено некоторое сходство тематики и направления дискуссий на площадках профессионального сообщества преподавателей (см. табл. 3). При этом очевидно, что ряд вопросов, которыми активно занимается Ассоциация преподавателей перевода (например, технология перевода удаленного перевода), не находит отражения в учебных пособиях и учебниках. Это объясняется возможностью быстро реагировать на происходящие социально-экономические изменения в формате устного общения и обсуждения и невозможностью быстро реагировать на профессиональные вызовы в письменно реализуемой и апробируемой дидактике - учебниках.

Результаты проведенного анализа профессионального / отраслевого ПД позволяют установить следующее:

1) тема «Преподавание перевода в удаленном формате» представляет собой новое направление в отрасли, которое приобрело на фоне глобальных социально-экономических процессов особую актуальность и масштаб, в том числе и в дидактике перевода. Профессиональное сообщество преподавателей демонстрирует своевременную реакцию на данный феномен на уровне обсуждения и поиска дидактических решений;

2) обнаруживается преемственность между обсуждаемыми проблемами в устном формате и их письменной реализацией в учебниках и пособиях;

3) наличие у Ассоциации преподавателей перевода собственного интернет-ресурса и возможности проведения мероприятий в течение года делают работу Ассоциации эффективным инструментом коммуникации в ПД.

\section{Выводы}

Сопоставление результатов контент- и дискурс-анализа трех востребованных и коммуникативно активных подвидов переводческого дискурса (научный переводоведческий, 
отраслевой профессиональный, дидактический ПД) позволило выделить его тематические доминанты, реализуемые в жанрах письменной, устной и интернет-опосредованной коммуникации. Научный ПД в проанализированном материале воплощается в жанрах доклада на конференции и научной статьи; профессиональный ПД - в жанрах доклада на мероприятиях переводческого сообщества, статьях в профессионально-ориентированных изданиях и комментариях или на форумах в формате интернет-коммуникации; дидактический ПД - в жанрах выступления на мероприятиях сообщества преподавателей, вебинара, учебного пособия. Жанровая палитра говорит о многообразии жанровых интеракций ПД, которые обнаруживают динамичный характер ввиду востребованного формата интернеткоммуникации. Анализ тематики коммуникации в ПД в 2020 г. свидетельствует о преемственности рассматриваемых дискурсивных практик ПД - большинство обсуждаемых тем пересекаются, что говорит о функциональной и семантической конгруэнтности дискурса при его интер- и полидискурсивности, также ин- тертекстуальности. Несмотря на схожесть дискурсивных практик в обсуждении актуальных вопросов теории и практики перевода, выявлен ряд отличительных черт и тенденций. В научном русскоязычном ПД реализуется тенденция к рассмотрению собственно научных взглядов и подходов в переводоведении, тогда как в научном ПД немецкоязычной лингвокультуры наблюдается тенденция верификации теории к практической деятельности переводчика и отрасли в целом, что сближает научный немецкоязычный ПД с немецкоязычным и русскоязычным профессиональным ПД. Дидактический ПД адекватно и своевременно реагирует на тренды профессионального ПД, отражая интеграцию наиболее актуальных для отрасли тем как в повестку дискуссий преподавателей перевода, так и в новые учебные пособия. При этом вопросы дидактики перевода остаются мало освещенными в научном и профессиональном ПД, а особенности взаимодействия вузов, организации практик и выпускных квалификационных работ анализируются только в пределах дидактического ПД.

\section{Таблииа 3. Тематические доминанты дидактического ПД}

\section{Table 3. Thematic dominants of didactic translation discourse}

\begin{tabular}{|c|c|c|c|}
\hline \multirow{2}{*}{ Темы } & \multicolumn{3}{|c|}{ Источники } \\
\hline & VIII & IX & $\mathbf{X}$ \\
\hline Формирование навыков работы с текстом & + & + & + \\
\hline Тренды переводческого рынка & + & + & - \\
\hline Преподавание в дистанционном формате & + & - & - \\
\hline Организация самостоятельной работы студентов & + & - & - \\
\hline Преподавание письменного перевода в дистанционном формате & + & - & - \\
\hline Медицинский перевод & + & - & - \\
\hline Локализация & + & - & - \\
\hline Перевод на ясный язык & + & - & - \\
\hline Деятельность письменного переводчика в современных условиях & + & - & - \\
\hline Специальный перевод & + & - & + \\
\hline $\begin{array}{l}\text { Современные подходы к преподаванию устного и письменного } \\
\text { перевода }\end{array}$ & + & - & + \\
\hline Организация практики студентов & + & - & + \\
\hline $\begin{array}{l}\text { Государственная и общественно-профессиональная аккредитация } \\
\text { для вузов }\end{array}$ & - & + & - \\
\hline $\begin{array}{l}\text { Научно-исследовательская работа студентов-переводчиков. Вы- } \\
\text { пускная квалификационная работа бакалавров и магистров }\end{array}$ & - & + & + \\
\hline $\begin{array}{l}\text { Взаимодействие вузов и переводческой отрасли в процессе под- } \\
\text { готовки переводчиков }\end{array}$ & - & + & - \\
\hline Синхронный перевод & - & + & + \\
\hline Аудиовизуальный перевод & - & + & + \\
\hline Перевод в различных дискурсах & - & - & + \\
\hline Перевод в профессиональной коммуникации & - & - & + \\
\hline
\end{tabular}


Каждый из рассмотренных подвидов ПД обладает особым инструментарием, коммуникативными каналами, традициями и форматами, определяющими тематические доминанты каждого из направлений дискурса. Научный ПД ориентирован на переводоведов, отраслевой ПД - на переводчиков-практиков, дидактический ПД - на преподавателей перевода. Взаимодействие участников ПД внутри перечисленных подвидов осуществляется в устной, письменной и компьютерно-опосредованной формах коммуникации. Каждый из подвидов ПД по-своему реагирует на внешние факторы развития цифровой эпохи 4.0: если научный ПД сохраняет традиции переводоведения, то отраслевой ПД более восприимчив к изменениям переводческой деятельности с учетом актуальных трендов отрасли, дидактический ПД занимает промежуточное место, поскольку на внедрение инноваций в процесс обучения и подготовки переводчиков требуется время, апробация и др. Следовательно, изучаемый дискурс, с одной стороны, имеет динамичный характер, а с другой - проявляет устойчивость развития.

Таким образом, в результате исследования типологизирован ПД, показаны экспланаторные возможности изучения ПД в русле интегративного подхода, развитие которого позволит представить системное описание ПД, его дискурсивных практик с позиции социокоммуникативного действия.

Интегративные исследования переводческой деятельности способствуют комплексному осмыслению коммуникативной программы переводчика в транскультурной локально и глобально опосредованной коммуникации и расширяют границы научного знания о переводческом дискурсе как гибридном дискурсе.

\section{СПИСОК ЛИТЕРАТУРЫ}

Власенко С. В., 2015. Переводческий дискурс: дилеммы определения и унификации понятия // Вестник Московского университета. Серия 22, Теория перевода. № 2. С. 124-144.

Воскобойник Г. Д., 2004. Тождество и когнитивный диссонанс в переводческой теории и практике// Вестник МГЛУ. Вып. 499. 181 с.

Гарбовский Н. К., 2010. Перевод и смысл: к постановке вопроса // Труды Высшей школы пе- ревода (ф-та) Моск. ун-та. Кн. 1. 2005-2010. М. : Изд-во Высшей школы перевода МГУ. С. 107-111.

Гарбовский Н. К., 2012. Русский переводной дискурс: миф или реальность // Русский язык и культура в зеркале перевода. М. : Изд-во Высшей школы перевода МГУ. С. 130-136.

Дондукова Г. П., 2012. Природа и сущность переводческого дискурса // Вестник Бурятской государственной сельскохозяйственной академии им. В.Р. Филиппова. № 1 (26). С. 155-160.

Каразия А. А., 2016. Англоязычный переводной дискурс как результат реализации переводческих стратегий : автореф. дис. ... канд. филол. наук. СПб. 24 с.

Краснопеева Е. С., 2015. О месте понятия «переводческие универсалии» в исследованиях переводного дискурса // Вестник Челябинского государственного университета. Филологические науки. Вып. 98, № 27 (382). С. 108-113.

Куницына Е. Д., 2009. Шекспир - Игра - Перевод. Иркутск : ИГЛУ. 434 с.

Куницына Е. Ю., 2018. Переводческий дискурс как пространство игры и метаигры переводчика // Переводческий дискурс: междисциплинарный подход : материалы II Междунар. науч.практ. конф. (г. Симферополь, 26-28 апреля 2018 г.). Симферополь : АРИАЛ. С. 238-340.

Кушнина Л. В., 2009. Теория гармонизации: опыт когнитивного анализа переводческого пространства. Пермь : ПНИПУ. 196 с.

Кушнина Л. В., Аликина Е. В., 2010. Система оценки качества устного последовательного перевода в свете теории гармонизации // Вестник Пермского университета. Вып. 4 (10). С. 46-51.

Левицкий А. Э., 2017. Дискурс и перевод // Переводческий дискурс: междисциплинарный подход : материалы I Bcepoc. науч.-практ. конф. (г. Симферополь, 27-29 апреля 2017 г.). Симферополь : АРИАЛ. С. 230-235.

Митягина В. А., 2017. Социопрагматическое измерение транслатологической парадигмы: коммуникативное действие в переводе // Вестник Волгоградского государственного университета. Серия 2, Языкознание. Т. 16, № 3. С. 30-40. DOI: https://doi.org/10.15688/jvolsu2.2017.3.3.

Митягина В. А., Наумова А. П., 2019. Professional Translators' Ethics in Workplace Communication // IOP Conference Series: Materials Science and Engineering. Vol. 483. The I International Scientific Practical Conference "Breakthrough Technologies and Communications in Industry" (20-21 November, Volgograd, Russia). DOI: https://doi.org/10.1088/1757-899X/483/1/012010.

Мишкуров Э. Н., 2012. Язык, «языковые игры» и перевод в современном лингвофилософс- 
ком и лингвокультурологическом осмыслении // Вестник Московского университета. Серия 22, Теория перевода. № 1. С. 5-15.

Наумова А. П., 2013. Институциональность профессионального дискурса переводчиков // Вестник Волгоградского государственного университета. Серия 2, Языкознание. № 2 (18). C. 104-109.

Наумова А. П., 2016. Языковая игра в профессиональном дискурсе переводчиков // Ноmо Loquens: Вопросы лингвистики и транслятологии. Вып. 9. С. 157-171.

Новикова, Э. Ю., 2017. Дискурсивная личность переводчика: переводческие компетенции и роли // Вестник Волгоградского государственного университета. Серия 2, Языкознание. T. 16, № 3. C. 90-102. DOI: https://doi.org/ 10.15688/jvolsu2.2017.3.9.

Писанова Т. В., 2011. Художественный переводческий дискурс в свете идей философской герменевтики // Вестник Московского государственного лингвистического университета. Вып. 617. С. 155-171.

Milton J., 2004. The Figure of the Factory Translator: University and Professional Domains in the Translation Profession // Claims, Changes and Challenges in Translation Studies. AmsterdamPhiladelphia : John Benjamins Publishing Company. P.169-179.

Wolf M., Fukari A., 2007. Constructing a Sociology of Translation. Amsterdam ; Philadelphia : John Benjamins. 230 p.

\section{ИСТОЧНИКИ}

I - Вестник Московского Университета. Серия 22, Теория перевода. 2020. № 1-4.

II - Переводческий дискурс: междисциплинарный подход : материалы IV Междунар. науч.-практ. конф. (г. Симферополь, 23-25 апреля 2020 г.). Симферополь : АРИАЛ, 2020.454 с.

III - Übersetzen und Dolmetschen 4.0. Neue Wege im digitalen Zeitalter. URL: https://www.uebersetzenin-die-zukunft.de/callforpapers (дата обращения: 20.11.2020).

$I V$ - Журнал переводчиков «Мосты». 2020. № 1-4. URL: http://www.rvalent.ru/Content_Most 2020.pdf(дата обращения: 17.11.2020).

$V$ - Международная переводческая конференция Translation Forum Russia 2020. URL: https:// tconference.ru/itogi-translation-forum-russia2020 (дата обращения: 18.11.2020).

$V I$ - Международная переводческая конференция UTICamp-2020. URL: https://2020.utic.eu/ program (дата обращения: 18.11.2020).
VII - Форум переводческого онлайн-сообщества Proz.com. URL: https://www.proz.com/forum (дата обращения: 19.11.2020).

VIII - Ассоциация преподавателей перевода. Успех во взаимодействии. URL: https://translationteachers.ru/events/kalendar-app (дата обращения: 19.11.2020).

$I X$ - Общероссийское методическое совещание по вопросам подготовки переводчиков. URL: https://translation-teachers.ru/news/ obshherossijskoe-metodicheskoe-soveshhan (дата обращения: 19.11.2020).

$X$ - Книги, вышедшие в 2020 году. URL: http:// www.rvalent.ru/knigi_2015_goda.html (дата обращения: 19.11.2020).

\section{REFERENCES}

Vlasenko S.V., 2015. Perevodcheskiy diskurs: dilemmy opredeleniya i unifikatsii ponyatiya [Translation Discourse: Dilemmas of Defining and Unifying the Concept]. Vestnik Moskovskogo universiteta. Seriya 22. Teoriya perevoda. [Moscow University Translation Studies Bulletin], no. 2, pp. 124-144.

Voskoboinik G.D., 2004. Tozhdestvo i kognitivnyy dissonans $\mathrm{v}$ perevodcheskoy teorii i praktike [Identity and Cognitive Dissonance in Translation Theory and Practice]. Vestnik Moskovskogo gosudarstvennogo lingvisticheskogo universiteta [Vestnik of Moscow State Linguistic University], iss. $499.181 \mathrm{p}$.

Garbovskiy N.K., 2010. Perevod i smysl: k postanovke voprosa [Translation and Meaning: Towards Defining the Subject Matter]. Trudy Vysshey shkoly perevoda (f-ta) Mosk. un-ta. Kn. 1. 2005-2010 [Works of the Higher School (Faculty) of Translation and Interpretation. Book 1. 2005-2010]. Moscow, Izd-vo Vysshey shkoly perevoda MGU, pp. 107-111.

Garbovskiy N.K., 2012. Russky perevodnoy diskurs: mif ili realnost [Russian Translation Discourse: Myth or Reality]. Russkiy yazyk $i$ kultura $v$ zerkale perevoda [Russian Language and Culture Reflected in Translation]. Moscow, Izd-vo Vysshey shkoly perevoda MGU, pp. 130-136.

Dondukova G.P., 2012. Priroda i sushchnost' perevodcheskogo diskursa [The Nature and Essence of Translator's Discourse]. Vestnik buryatskoy gosudarstvennoy selskokhozyaystvennoy akademii im. V. R. Filippova [Vestnik of the Buryat State Academy of Agriculture named after V.R. Philippov], no. 1 (26), pp. 155-160. 
Karaziya A.A., 2016. Angloyazychnyy perevodnoy diskurs kak rezul'tat realizatsii perevodcheskikh strategiy : avtoref. dis. ... kand. filol. nauk. [English Translation Discourse as a Result of the Translation Strategies Implementation. Cand. philol. sci. abs. diss.]. Saint Petersburg. 24 p.

Krasnopeyeva E.S., 2015. O meste ponyatiya «perevodcheskie universalii» $\mathrm{v}$ issledovaniyakh perevodnogo diskursa [On the Place of Translation Universals Concept in Translated Discourse Research]. Vestnik Chelyabinskogo gosudarstvennogo universiteta. Filologicheskie nauki [Bulletin of Chelyabinsk State University. Philology Sciences], iss. 98, no. 27 (382), pp. 108-113.

Kunitsyna E.Yu., 2009. Shekspir - Igra - Perevod [Shakespeare - Play - Translation]. Irkutsk, IGLU. 434 p.

Kunitsyna E.Yu., 2018. Perevodcheskiy diskurs kak prostranstvo igry i metaigry perevodchika [Translation Discourse as a Space of Game and Metagame of the Translator]. Perevodcheskiy diskurs: mezhdistsiplinarnyy podkhod : materialy II Mezhdunar. nauch.-prakt. konf. (g. Simferopol, 26-28 aprelya 2018 g.) [Translation Discourse: Interdisciplinary Approach. Proceedings of the $2^{\text {nd }}$ International Scientific and Practical Conference. Simferopol, 26-28 April, 2018]. Simferopol, ARIAL Publ., pp. 238-340.

Kushnina L.V., 2009. Teoriya garmonizatsii: opyt kognitivnogo analiza perevodcheskogo prostranstva [Harmonization Theory: Experience in Cognitive Analysis of Translation Space]. Perm, PNIPU. 196 p.

Kushnina L.V., Alikina, E.V., 2010. Sistema otsenki kachestva ustnogo posledovatel'nogo perevoda v svete teorii garmonizatsii [Quality Assessment System of Consecutive Interpretation in Light of Theory of Harmonization]. Vestnik Permskogo Universiteta [Perm University Herald], no. 4 (10), pp. 46-51.

Levitsky A.E., 2017. Diskurs i perevod [Discourse and Translation]. Perevodcheskiy diskurs: mezhdistsiplinarnyy podkhod : materialy I Vseros. nauch.-prakt. konf. (g. Simferopol, 27-29 aprelya 2017 g.) [Translation Discourse: Interdisciplinary Approach. Proceedings of the $1^{\text {st }}$ International Scientific and Practical Conference. Simferopol, 27-29 April, 2017]. Simferopol, ARIAL Publ., pp. 230-235.

Mityagina V.A., 2017. Sotsiopragmaticheskoe izmerenie translatologicheskoy paradigmy: kommunikativnoe deystvie v perevode [SocioPragmatic Measurement of Translatology
Paradigm: Communicative Action in Translation]. Vestnik Volgogradskogo gosudarstvennogo universiteta. Seriya 2, Yazykoznanie [Science Journal of Volgograd State University. Linguistics], vol. 16, no. 3, pp. 30-40. DOI: https://doi.org/10.15688/ jvolsu2.2017.3.3.

Mityagina V.A., Naumova A.P., 2019. Professional Translators' Ethics in Workplace Communication. IOP Conference Series: Materials Science and Engineering. Vol. 483. The $1^{\text {st }}$ International Scientific Practical Conference "Breakthrough Technologies and Communications in Industry" (20-21 November, Volgograd, Russia). DOI: https:// doi.org/10.1088/1757-899X/483/1/012010.

Mishkurov E.N., 2012. Yazyk, «yazykovye igry» i perevod v sovremennom lingvofilosofskom i lingvokulturologicheskom osmyslenii [Language, "Language Games" and Translation in Modern Linguistic, Philosophic, and Cultural Studies Perspectives]. Vestnik Moskovskogo universiteta. Seriya 22. Teoriya perevoda. [Moscow University Translation Studies Bulletin], no. 1, pp. 5-15.

Naumova A.P., 2013. Institutsionalnost professionalnogo diskursa perevodchikov [Institutionality of Professional Translators' Discourse]. Vestnik Volgogradskogo gosudarstvennogo universiteta. Seriya 2, Yazykoznanie [Science Journal of Volgograd State University. Linguistics], no. 2 (18), pp. 104-109.

Naumova A.P., 2016. Yazykovaya igra v professionalnom diskurse perevodchikov [Language Play in Translators Professional Discourse]. Homo Loquens: Voprosy lingvistiki $i$ translyatologii, no. 9, pp. 157-171.

Novikova E.Yu., 2017. Diskursivnaya lichnost perevodchika: perevodcheskie kompetentsii i rolevoy portret [Discursive Personality of the Translator: Translation Competencies and Role Portrait]. Vestnik Volgogradskogo gosudarstvennogo universiteta. Seriya 2, Yazykoznanie [Science Journal of Volgograd State University. Linguistics], vol. 16, no. 3, pp. 90-102. DOI: https://doi.org/10.15688/jvolsu2.2017.3.9.

Pisanova T.V., 2011. Khudozhestvennyy perevodcheskiy diskurs v svete idey filosofskoy germenevtiki [Artistic Interpretative Discourse in Philosophical Hermeneutics Ideas]. Vestnik Moskovskogo gosudarstvennogo lingvisticheskogo universiteta [Vestnik of Moscow State Linguistic University], iss. 617, pp. 155-171.

Milton J., 2004. The Figure of the Factory Translator: University and Professional Domains in the Translation Profession. Claims, Changes and 
Challenges in Translation Studies. Amsterdam, Philadelphia, John Benjamins, pp. 169-179.

Wolf M., Fukari A., 2007. Constructing a Sociology of Translation. Amsterdam, Philadelphia, John Benjamins. $230 \mathrm{p}$.

\section{SOURCES}

I - Vestnik Moskovskogo universiteta. Seriya 22. Teoriya perevoda. [Moscow University Translation Studies Bulletin], 2020, no. 1-4.

II - Perevodcheskiy diskurs: mezhdistsiplinarnyy podkhod: materialy IV Mezhdunar. nauch.-prakt. konf. (g. Simferopol, 23-25 aprelya 2020 g.) [Translation Discourse: Interdisciplinary Approach. Proceedings of the $4^{\text {th }}$ International Scientific and Practical Conference. Simferopol, 23-25 April, 2020]. Simferopol,ARIALPubl., 2020.454p.

III - Übersetzen und Dolmetschen 4.0. Neue Wege im digitalen Zeitalter. URL: https://www.uebersetzen-in-die-zukunft.de/callforpapers (accessed 20 November 2020).

IV - Zhurnal perevodchikov "Mosty» [Translation Journal "Mosty"], 2020, no. 1-4. URL: http:// www.rvalent.ru/Content Most 2020.pdf (accessed 17 November 2020).

V-Mezhdunarodnaya perevodcheskaya konferentsiya Translation Forum Russia 2020
[International Translation Conference Translation Forum Russia 2020]. URL: https:// tconference.ru/itogi-translation-forum-russia2020 (accessed 18 November 2020).

VI - Mezhdunarodnaya perevodcheskaya konferentsiya UTICamp-2020 [International Translation Conference UTICamp-2020]. URL: https://2020.utic.eu/program (accessed 18 November 2020).

VII-Forum perevodcheskogo onlayn-soobshchestva Proz.com [Forum of the Translation Online Community Proz.com]. URL: https:// www.proz.com/forum (accessed 19 November 2020).

VIII-Assotsiatsiya prepodavateley perevoda. Uspekh vo vzaimodeystvii [Translation Teachers Association. Success in Collaboration]. URL: https://translation-teachers.ru/events/kalendarapp (accessed 19 November 2020).

IX-Obshcherossiyskoe metodicheskoe soveshchanie po voprosam podgotovki perevodchikov [AllRussian Methodological Meeting on Translators Training]. URL: https://translation-teachers.ru/ news/obshherossijskoe-metodicheskoesoveshhan (accessed 19 November 2020).

$X$ - Knigi, vyshedshie v 2020 gody [Books Published in 2020]. URL: http://www.rvalent.ru/ knigi_2015_goda.html (accessed 19 November 2020).

\section{Information About the Authors}

Elina Yu. Novikova, Doctor of Sciences (Philology), Professor, Department of Translation Theory and Practice, Volgograd State University, Prosp. Universitetsky, 100, 400062 Volgograd, Russia, novelina@volsu.ru, https://orcid.org/0000-0003-4442-9071

Anna P. Naumova, Senior Lecturer, Department of Translation Theory and Practice, Volgograd State University, Prosp. Universitetsky, 100, 400062 Volgograd, Russian Federation, anaumova9@volsu.ru, https://orcid.org/0000-0003-4002-4915

\section{Информация об авторах}

Элина Юрьевна Новикова, доктор филологических наук, профессор кафедры теории и практики перевода, Волгоградский государственный университет, просп. Университетский, 100, 400062 г. Волгоград, Россия, nov-elina@volsu.ru, https://orcid.org/0000-0003-4442-9071

Анна Петровна Наумова, старший преподаватель кафедры теории и практики перевода, Волгоградский государственный университет, просп. Университетский, 100, 400062 г. Волгоград, Россия, anaumova9@volsu.ru,https://orcid.org/0000-0003-4002-4915 